\title{
Wireless Sensor Enabled Public Transportation System
}

\author{
Sunil Praneel Narayan1, Mansour H. Assaf1, Shalvindra Krishneel Prasad2 \\ ${ }^{1}$ School of Engineering and Physics, University of South Pacific, Suva, Fiji \\ ${ }^{2}$ Pace Technologies Ltd, Nadi, Fiji \\ Email: sunilpraneelnarayan2000@yahoo.com, assaf m@usp.ac.fi, shalvindra@outlook.com
}

Received 17 March 2015; accepted 17 May 2015; published 20 May 2015

Copyright (C) 2015 by authors and Scientific Research Publishing Inc.

This work is licensed under the Creative Commons Attribution International License (CC BY). http://creativecommons.org/licenses/by/4.0/

(c) (i) Open Access

\begin{abstract}
Automatic Vehicle Identification (AVI) in real time is becoming an urgent necessity due to rapid increase in the number of vehicles on roads. The Radio Frequency Identification (RFID) Technology can be used for vehicle identification to gather information in real-time from roads by getting the vehicles location from RFID readers placed in the vehicle. This paper focuses on designing the Public Vehicle Location System (PVLS). The proposed structure consists of passive RFID tags placed at various locations on the chosen route, RFID reader on the Bus, wireless communication with a PC and commanding software (RFID reader and database structure), also PVLS applications and website. The designed system controls, manages and monitors the performance of RFID readers. It also filters and stores the information in an appropriate format so that it could be used without difficulty in the application system and website. The system implemented by using RFID is placed in the Bus which is programmed by Visual C\# 2008 with Compact .Net Framework.
\end{abstract}

\section{Keywords}

RFID, Vehicle, Location, Tracking, Public Transport

\section{Introduction}

The value of time is precious in today's fast paced community and nobody can afford to waste long hours waiting for a public transport [1]. Due to this time crunch, it will be of convenience to the public if the precise arrival information, real time status, travel duration, etc., are available so that they can choose other alternatives. Presently, one cannot completely rely on the fixed bus timings provided by Bus Companies on their websites as factors such as traffic and in some cases, accidents, delay the arrival of buses. Management of bus schedules at the bus stations thus becomes very difficult and unpredictable. Hence, there is an urgent need to develop an efficient tracking system to satisfy the needs of the commuters. RFID evidently is not a new technology; rather its 
origin dates back to World War II [2]. It is a programmed identification technology that allows for noncontact reading of data, thereby making it attractive for vehicles [3].

It is usually operated with a tiny battery. The network lifetime is mainly affected by the targeted application and capacity of the battery. Hence, minimizing communications among the nodes is one of the essential requirements in designing a network of wireless sensor nodes [4]. When Radio Frequency Identification (RFID) technologies are coupled to a Wireless Sensor Network (WSN), new features are provided such as tracking, identification and localization. An RFID tag is incorporated into the object to be tracked or localized using radio signals. Among the various applications that can benefit from RFID-based localization and tracking technologies, vehicle identification and tracking appears to be a promising field [5] [6].

An RFID tag is attached to a vehicle which is identified as soon as it enters the RFID reader's range. The data stored in the tag's memory are captured by the reader and transmitted to a server through a public or private network. The rest of the paper is organized as follows: Section 2 explains the RIFD Technology; Section 3 discusses the structure of PVLS based on RFID; Section 4 describes system software and data gathering; Section 5 gives the application of PVLS; Finally, the conclusion is given in Section 6.

\section{Related Work}

In an endeavor to improve efficiency and security in transport systems, research is being done on RFID technology in different applications such as smart electronic parking, electronic ticketing, toll collection, virtual route tracking, and digital traffic light control and with some other RFID applications [4] [7]. The following literatures are several designs of such systems researched and implemented.

The location determination methods most commonly used in vehicles are communication mechanisms such as GSM, GPRS, GPS and a satellite. The GSM and GPRS coverage in remote locations is usually poor and the GPS system does not function well in areas which do not have proper line-if-sight to a GPS satellite [8]-[10]. In environments where GPS illumination is poor and weak, other wireless technologies can be implemented. RFID systems can be employed to determine the location of assets or objects in real time. The location data given from GPS devices is from a distance of 10 to 15 meters which is not precise. The PVLS designed using RFID technology in the project gives better results compared to other technologies, such as GSM, GPRS, GPS, etc. [11]-[13].

A framework with moving vehicles with attached passive tags was proposed by Y. Zhang in 2009 [14] where the tags were located by RFID readers which were installed at the roadsides near the intersections. The idea was to improve the intelligent transport system of the traffic with real time status. The traffic sampling data was used to avoid multiple data collision which was a very challenging issue in his approach. The information of road intersection was preloaded in the RFID reader to determine the location. The road status throughout the city was evaluated by tracking individual vehicle's information. The system was implemented and tests were conducted to evaluate the feasibility and functionality of the proposed framework.

Due to major advancements made to RFID technologies, various types of applications involving vehicles have been deployed, such as automatic toll gate payment, fleet management, safe navigation and intelligent transport systems. Most of these applications integrate a vehicle identification process using an RFID tag. When tracking becomes an application requirement, it is common to use GPS positioning to localize the vehicles. However, depending on the area where the vehicle is located, accuracy may not be adequate due to the high cost of the GPS receiver. A. Araar and H. Khali in 2012 [15] proposed to investigate, at a system level, the incorporation of RFID technology and clustered WSN in order to identify and track vehicles to substitute GPS-based systems. The WSN is designed using smart nodes which incorporate an RFID reader with a wireless communication interface. The author's analyzed the benefits of using a time-slotted approach and data fusion performed at the node level on the system throughput expressed as the number of vehicle tags read per second. Two metrics, energy delay and throughput, were used to evaluate the proposed fusion schemes. When deployed in desert-like regions, solar panels are recommended to avoid cluster head election. Simulation results showed when it is recommended to use RFID tag fusion and when it is not.

\section{RFID Technology}

\subsection{RFID System Components}

An RFID system is basically an integrated combination of various components which work together for detec- 
tion and identification of objects or persons. These are the components which are primarily responsible for working of any RFID system whether basic or complex [16]. Although there can always be additional components associated with RFID systems like sensors etc. but the following are amongst the key components of these systems:

- RFID Tag

- RFID reader with an antenna and transceiver

- A host computer

\subsection{Advantages}

RFID technologies show some strengths and abilities that cannot be found using many conventional technologies to help automate processes and track products. Kaur [17] identified the following beneficial attributes that RFID technologies possess:

1. Reduction of human involvement which reduces costs and errors

2. Read/write memory capability

3. Large amounts of data can be stored to a unique identifier

4. Implementation of unique IDs is simpler with RFID than with barcodes

5. Tags can be read at any time simultaneously, reducing time and increases accuracy

\subsection{Applications}

RFID technology provides a variety of solutions to common problems faced by individuals and large complex businesses daily. An overview of some areas that are taking advantage of RFID technologies and providing are real time solutions to everyday problems is listed as follows:

- Instance or Class identification

- Location Tracking

- Data and Information Transfer

\section{System Architecture}

The design of the PVLS consists of a PC (server) and website. The PC contains the database and the system applications. The RFID reader of PVLS is simulated to evaluate that the system works and test its ability to collect and manage the arrival time information of buses from several tags in real-time. The reader is programmed to connect the PVLS with database, and to arrange the information that is received from readers in appropriate format to be used in the application system and website. Wireless communication (Wi-Fi) system is used to connect the PC with the readers.

The first step in the PVLS is to attach RFID reader to a vehicle that will identify the tags on various bus stops. It is suggested that the data being stored in a tag only be its unique tag ID and without any other details of the vehicle, so to keep the privacy of the vehicles. In this form no sensitive information is available, and prevent any unauthorized access to the data.

The proposed system consists of one RFID reader placed in the bus which wirelessly connects to the host PC over Wi-Fi, which has the system's database installed (SQL Server). The reader reads the tags from various stops and sends the information to the database. The users are located at their various bus stations, waiting for the bus. Figure 1 shows the route of the University bus on which the system was trialed.

The operating system for the reader is Windows CE 5.0. The Reader is programmed in Microsoft Visual C\# 2008 using Microsoft. NET Framework 3.5 environment and the database system is designed using Microsoft SQL express 2005.

The hardware components of the PVLS consists of a RFID reader and tags, and a host PC.

In brief, the following components are used for building PVLS system:

- Four computer devices (one as RFID reader via Personal Computer)

- Wi-Fi system

- Microsoft Visual C\# 2008 with .NET Compact Framework 3.5

- Microsoft SQL Express 2005

- Apache Web Server with PHP extension (system website) 


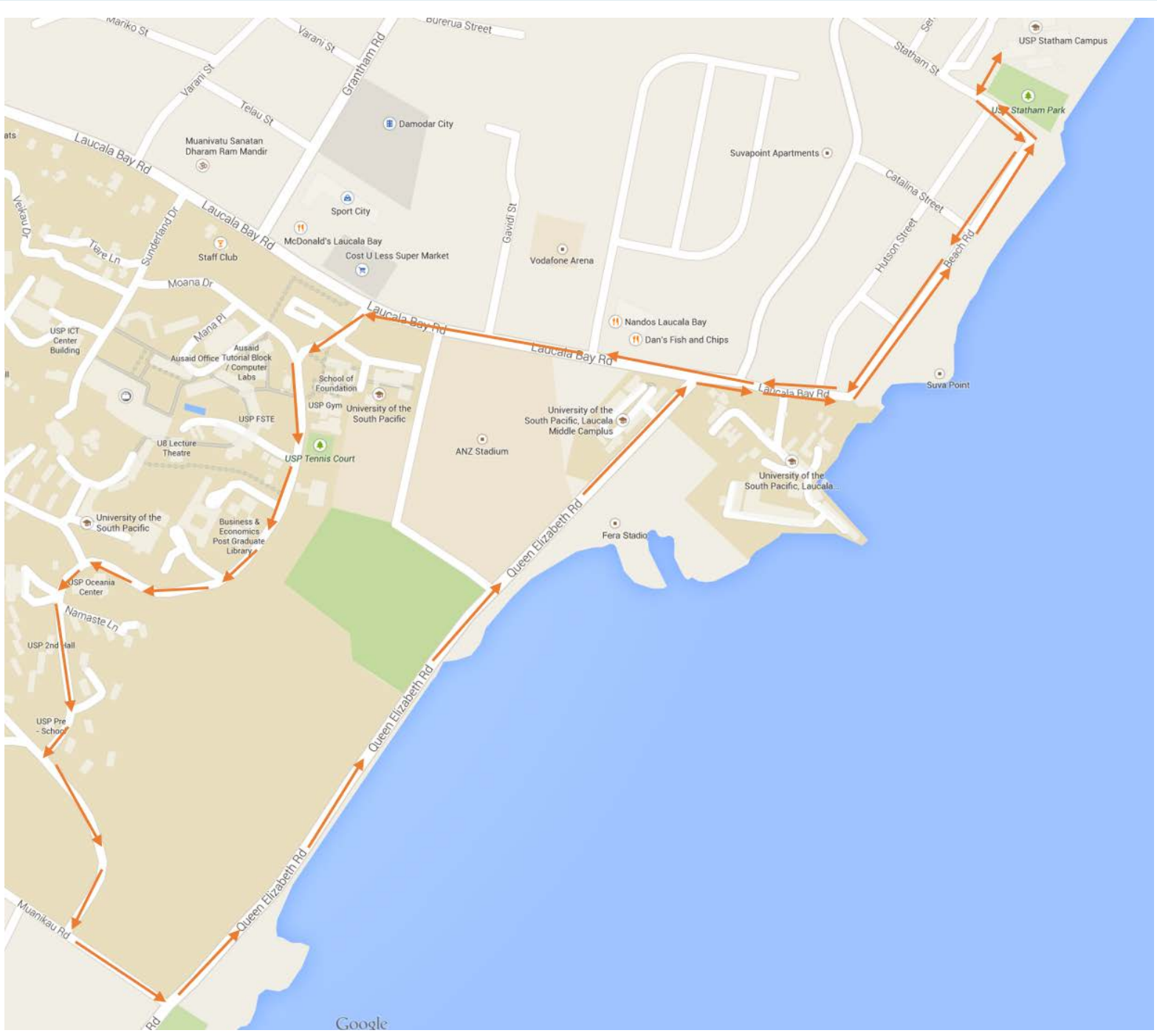

Figure 1. Route of the tested location tracking system.

Figure 2 shows the algorithm for the reader software which reads tags and stores the location information the database. Figure 3 depicts the basic algorithm used by the website to present the information in a user friendly way to the users of the system.

\section{RFID Hardware}

The reader used for the above project, shown in Figure 4, is a SAAT-H522, which is a portable active reader, operating at $2.45 \mathrm{GHZ}$ band. It has a very high performance, flexible and powerful reader with broader functions and a combination of various other features. SAAT-H522 is portable and user friendly together which is easy to use. The reader is suitable for person location, asset tracking, traffic vehicle management, etc.

\section{Description of Public Vehicle Location System}

The following are some conditions taken into consideration for whether the RFID technology is useful in the Public Vehicle Location system:

- The tags may be affected by change of weather

- There are many disturbances which may affect RF wave communication

- Vehicle routes are not well defined

- Equipment is difficult to install at the terminals as chances are it may be stolen 


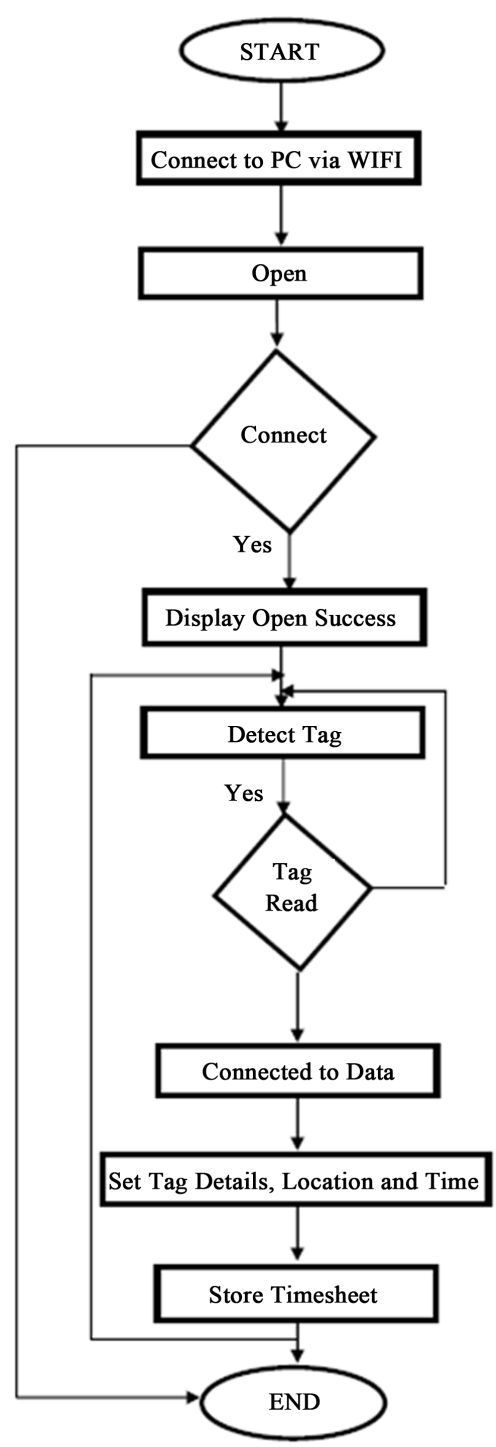

Figure 2. The flowchart of the PVLS system architecture.

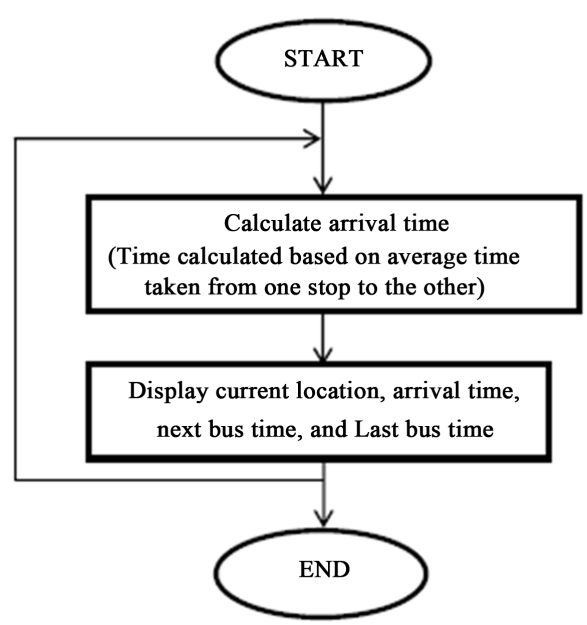

Figure 3. The flow chart showing displays at different locations. 


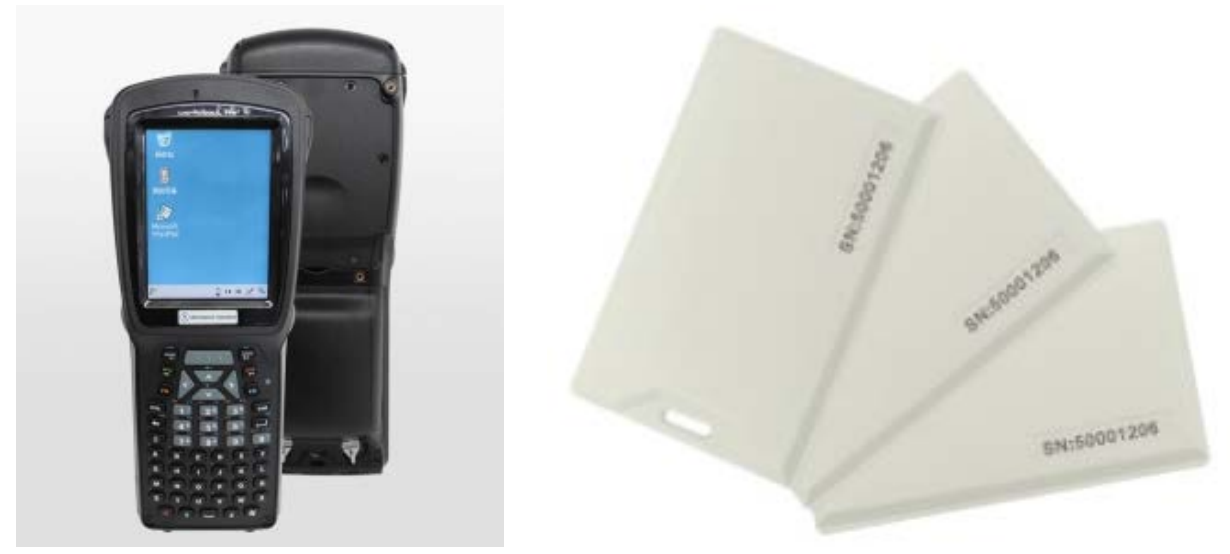

Figure 4. SAAT-522 RFID hand held reader and passive tag.

- Reader may not send data to PC over Wi-Fi properly

- Reader may read tags which are opposite to each other on the road

Based on the above considerations and the parameters identified to determine success in RFID communication, distance, penetration, speed, the equipment capabilities in meeting project requirements were tested. The project planned was categorized into 2 sets. The first stage was to test how the effectiveness of the RFID communication system is affected by the parameters such as distance, speed and penetration and in the second stage trials were run to test the effectiveness of the system in different conditions to simulate the real operation scenario.

\subsection{Database}

All RFID systems require smart database for storing all data received from readers in real-time. Microsoft SQL Express 2005 Management Studio was selected to build the PVLS's database, as it is robust, compatible with Microsoft Visual Studio 2008 and Visual C\# .Net CF supports special Application Programming Interface (API) to communicate with the reader. Also, SQL has fast response and effective with robust database queries, such as querying many tables in one request. SQL Server is necessary to build several tables for PVLS system, each one for specific purpose. These tables are: tag ID table, vehicles location table, timesheet, and authorized users table.

\subsection{Tag ID Table}

This table is constructed to store the location of the bus as it moves from one location to the other. The ID of the tags identify the tag's location on the route. The information from the table is shown below in Figure 5.

\subsection{Timesheet Table}

This table, data shown in Figure 6, is constructed to store the time of the bus as it moves from one location to the other and at various bus stops.

\section{Public Vehicle Location System}

PVLS is composed of two parts which are main program and websites. The main program comprises the Reader, database management and applications. The PC controls the connection and communication of the RFID reader, and database. The PVLS application depends on the data received from RFID readers (Figure 7).

\subsection{The Table of PVLS}

The information on this web page, shown in Figure 8, is updated every ten seconds and it can be update any time the administrator or users require. The web page will only be viewed by the administrator in the Bus with the reader. The information from this web page is displayed to their other domain respectively depending on their location. 


\begin{tabular}{|c|c|}
\hline 52506125 & Marine Campus \\
\hline 52506173 & Old Gymnasium \\
\hline 52506175 & Statham Campus Exit \\
\hline 52506177 & Nasese Road \\
\hline 52506181 & Laucala Campus Main Gate \\
\hline 52506182 & Laucala Rear Gate \\
\hline 52506184 & Junction \\
\hline 52506188 & Namaste Lane \\
\hline 52506189 & FBE Car Park \\
\hline 52506191 & National Stadium Rear Entrance \\
\hline 52506196 & Bulsara Park \\
\hline 52506203 & Beach Road Corner \\
\hline 52506210 & Catalina Ln Junction \\
\hline 52506211 & Laucala Campus Bus Stop \\
\hline 52506212 & Marine Campus \\
\hline 52506125 & \\
\hline
\end{tabular}

Figure 5. The tag ID and its location.

\begin{tabular}{|c|c|c|c|}
\hline 21 & 5/8/2013 3:30:46 PM & 5/8/2013 3:31:20 PM & 52506203 \\
\hline 24 & 5/8/2013 3:30:46 PM & 5/8/2013 3:31:20 PM & 52506212 \\
\hline 30 & 5/8/2013 3:30:46 PM & 5/8/2013 3:31:21 PM & 52506181 \\
\hline 31 & 5/8/2013 3:30:46 PM & 5/8/2013 3:31:20 PM & 52506177 \\
\hline 33 & 5/8/2013 3:30:46 PM & 5/8/2013 3:31:20 PM & 52506210 \\
\hline 36 & 5/8/2013 3:30:46 PM & 5/8/2013 3:31:20 PM & 52506175 \\
\hline 38 & 5/8/2013 3:30:47 PM & 5/8/2013 3:31:21 PM & 52506189 \\
\hline 39 & 5/8/2013 3:30:47 PM & 5/8/2013 3:31:20 PM & 52506191 \\
\hline 44 & 5/8/2013 3:30:47 PM & 5/8/2013 3:31:21 PM & 52506188 \\
\hline 47 & 5/8/2013 3:30:47 PM & 5/8/2013 3:31:22 PM & 52506182 \\
\hline 50 & 5/8/2013 3:30:48 PM & 5/8/2013 3:31:21 PM & 52506196 \\
\hline 53 & 5/8/2013 3:30:49 PM & $\begin{array}{c}\text { 5/10/2013 9:50:13 } \\
\text { AM }\end{array}$ & 52506173 \\
\hline 54 & 5/8/2013 3:30:49 PM & 5/8/2013 3:31:21 PM & 52506184 \\
\hline
\end{tabular}

Figure 6. The Timesheet of the Bus at different locations as seen via the website.

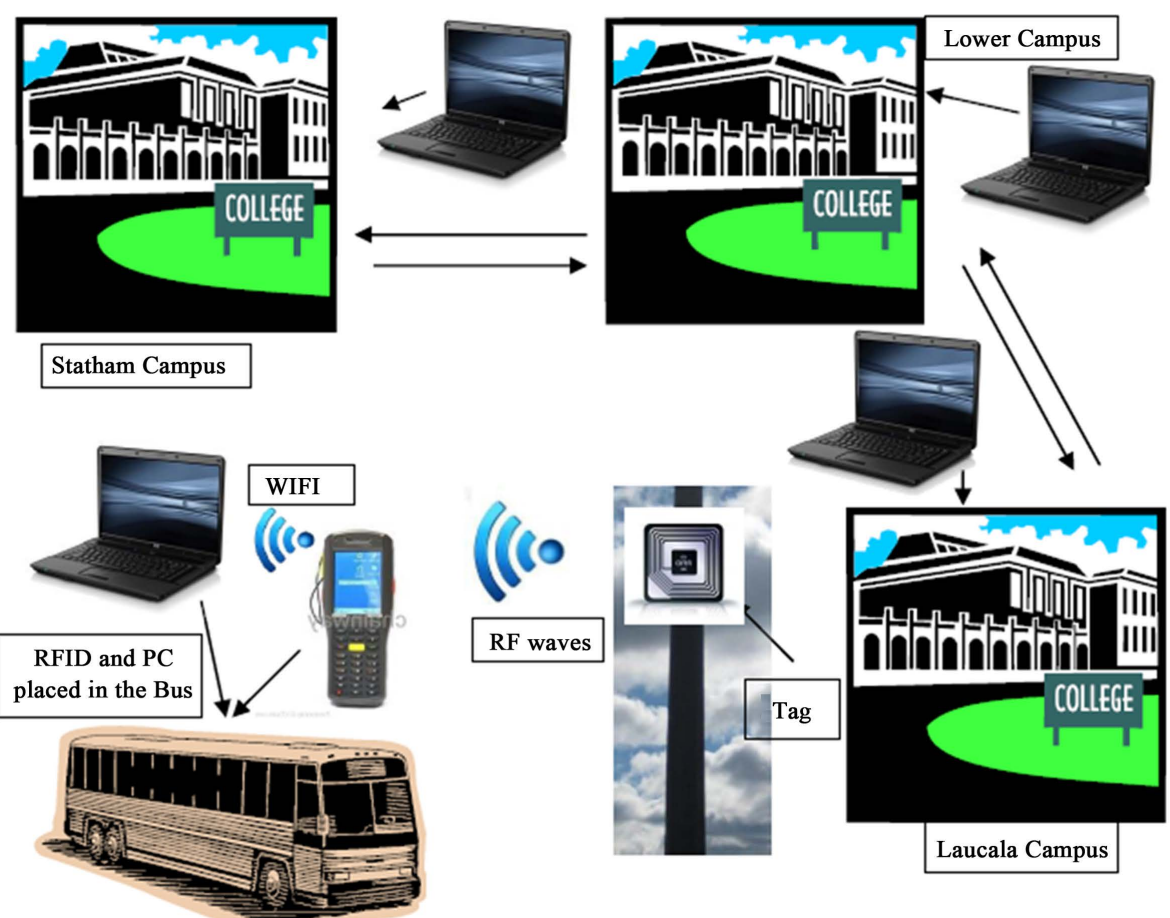

Figure 7. The public vehicle location system architecture. 


\begin{tabular}{|l|l|l|l|}
\hline $\mathbf{5 2 5 0 6 2 1 2}$ & Laucala Campus Bus Stop & 01 May 2013 & $13: 16: 27$ \\
\hline $\mathbf{5 2 5 0 6 1 8 1}$ & Laucala Campus Main Gate & 01 May 2013 & $13: 15: 54$ \\
\hline $\mathbf{5 2 5 0 6 1 7 3}$ & Old Gymnasium & 01 May 2013 & $13: 15: 15$ \\
\hline $\mathbf{5 2 5 0 6 2 1 0}$ & Beach Road Corner & 01 May 2013 & $13: 13: 34$ \\
\hline $\mathbf{5 2 5 0 6 2 0 3}$ & Statham Campus Main Gate & 01 May 2013 & $13: 13: 09$ \\
\hline $\mathbf{5 2 5 0 6 1 8 4}$ & Junction & 01 May 2013 & $13: 10: 01$ \\
\hline $\mathbf{5 2 5 0 6 1 7 7}$ & Nasese Road & 01 May 2013 & $13: 07: 56$ \\
\hline $\mathbf{5 2 5 0 6 1 8 2}$ & Laucala Rear Gate & 01 May 2013 & $13: 07: 14$ \\
\hline $\mathbf{5 2 5 0 6 2 1 1}$ & Catalina Ln Junction & 01 May 2013 & $13: 01: 43$ \\
\hline $\mathbf{5 2 5 0 6 1 8 8}$ & Namaste Lane & 01 May 2013 & $13: 01: 13$ \\
\hline $\mathbf{5 2 5 0 6 1 8 9}$ & FBE Car Park & 01 May 2013 & $12: 59: 56$ \\
\hline $\mathbf{5 2 5 0 6 2 1 2}$ & Laucala Campus Bus Stop & 01 May 2013 & $12: 59: 25$ \\
\hline
\end{tabular}

Figure 8 . The data seen by an administrator via the website.

\subsection{The Laucala Campus}

The users at the Laucala campus will be able to see the current location of the bus, the arrival time of the bus and also, the arrival time of the last bus. This information can be displayed at the bus stations and will be of great help to the users. As shown in Figure 9, the bus has left Laucala Campus and it has arrived at FBE Car Park where a tag has been installed. The reader reads the tag and the information goes into the database which is updated in the Web. The information shown below shows that the arrival time at Laucala Campus will be 10:38 am and the next bus after arriving will come at 10:58 am and the last Bus will come at 6:00 pm.

\subsection{The Marine Campus}

The users at the Marine campus will be able to see the current location of the bus, the arrival time of the bus and also, the arrival time of the last bus. This information can be displayed at the bus stations and will be of great help to the users. As shown in Figure 10, the bus has left Laucala Campus and it has arrived at FBE Car Park where a tag has been installed. The reader reads the tag and the information goes into the database which is updated in the Web. The information shown below shows that the arrival time at the Marine Campus will be 10:19 am and the next bus after arriving will come at 10:54 am and the last Bus will come at 6:10 pm.

\subsection{The Statham Campus}

The users at the Statham campus will be able to see the current location of the bus, the arrival time of the bus and also, the arrival time of the last bus. This information can be displayed at the bus stations and will be of great help to the users. As shown in Figure 11, the bus has left Laucala Campus and it has arrived at FBE Car Park where a tag has been installed. The reader reads the tag and the information goes into the database which is updated in the Web. The information shown below shows that the arrival time at the Statham Campus will be 10:26 am and the next bus after arriving will come at 11:01 am and the last Bus will come at 6:15 pm.

\section{Conclusions}

The rapid increase of vehicles on roads encourages the researchers to get new ideas or algorithms to be used in RFID technology in vehicles. RFID is becoming a promising technology for the transportation industry with a potential that is not fully utilized. The research focused on how technologies of identification by RFID can be used to build public transport location in real time by collecting information from the tags which is placed in various Bus Stops. The research also focused on the actual RFID hardware implementation such as the passive tags and the reader that is used to track the University Bus as it moves from one station to the other.

The implemented project of the PVLS structure is designed where every vehicle has a RFID reader in place. The information at various stops, where a tag is read, transmits the location in real-time to the reader which sends the data via Wi-Fi to the server in the personal computer in the vehicle. Then the information from the database is processed by the website and made available to the clients at different stations. The results obtained from the actual studies show that the reader to the clients was realistic and very reliable. The information received 


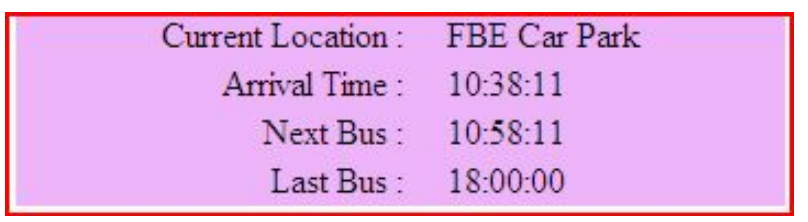

Figure 9. The real-time location of bus at Laucala from the website.

\begin{tabular}{|rl|}
\hline Current Location: & FBE Car Park \\
Arrival Time : & $10: 19: 08$ \\
Next Bus: & $10: 54: 08$ \\
Last Bus : & $18: 10: 00$ \\
\hline
\end{tabular}

Figure 10. The real-time location of bus at Marine from application.

\begin{tabular}{rl|} 
Current Location: & FBE Car Park \\
Arrival Time : & $10: 26: 02$ \\
Next Bus : & $11: 01: 02$ \\
Last Bus : & $18: 15: 00$
\end{tabular}

Figure 11. The real-time location of bus at Statham from the website.

from RFID system at various bus stations gains benefits by providing the arrival time of the bus to the students and passengers waiting for the University Bus. Since the information is provided in the form of a web site, it can be dispensed to the users not only at the bus stops, but also to their personal devices such as smart phones and tablets.

\section{References}

[1] Lieshout, M. (2007) Challenges and Policy Options. In: RFID Technologies: Emerging Issues, European Commission Joint Research Centre (EUROPA), 32-33.

[2] RFID Tribe-History of RFID Technology. http://www.rfidjournal.com/articles/view?1338/2

[3] Ahsan, K., Shah, H. and Kingston, P. (2010) RFID Applications: An Introductory and Exploratory Study. International Journal of Computer Science Issues, 7, 1-7.

[4] Caffery, J. and Gordon, L. (2010) Subscriber Location in CDMA Cellular Network. IEEE Transactions on Vehicular Technology, 47, 406-416.

[5] Elisabeth, I. and Kemeny, Z. (2010) The RFID Technology and Its Current Applications. In Proceedings of the Modern Information Technology in the Innovation Process of the Industrial Enterprises, 29-36.

[6] Aguiar, A., Nunes, F., Silva, M. and Elias, D. (2012) Personal Navigator for a Public Transport System Using RFID Ticketing. Department of Innovation Engineering, University of Salento, Lecce.

[7] Charlebois, P.-O. (2004) Radio Frequency Indetification (RFID): Principles and Applications. Electromagnetic Fields and Waves, McGill University, Montreal.

[8] Saravanan, S. and Kavitha, T. (2012) Vehicle Navigation and Obstacle Detection System Using RFID and GSM. Journal of Theoretical and Applied Information Technology, 38, 206-209.

[9] Chan, E., Baciu, G. and Mark, S. (2009) Using Wi-Fi Signal Strength to Localize in Wireless Sensor Networks. WRI International Conference on Communications and Mobile Computing, Yunnan, 6-8 January 2009, 538-542. http://dx.doi.org/10.1109/cmc.2009.233

[10] Figueiras, J., Schwefel, H. and Kovacs, I. (2005) Accuracy and Timing Aspects of Location Information Based on Signal-Strength Measurements in Bluetooth. IEEE 16th International Symposium on Personal, Indoor and Mobile Radio Communications, Berlin, 11-14 September 2005, 2685-2690. 
[11] What is GPS. Garmin Ltd. https://www8.garmin.com/aboutGPS/

[12] Jami, I., Ali, M. and Ormondroyd, R.F. (1999) Comparison of Methods of Locating and Tracking Cellular Mobiles. IEEE Colloquium on Novel Methods of Location and Tracking of Cellular Mobiles and Their System Applications, 23, 1/1-1/6.

[13] Palazzi, C.E., Ceriali, A. and Monte, M.D. (2009) RFID Emulation in Rfidi Environment. In: International Symposium on Ubiquitous Computing, Beijing.

[14] Zhang, Y. (2009) RFID-Based Tracking in Supporting Real-Time Urban Traffic Information. IEEE 5th International Joint Conference on INC, IMS and IDC, Seoul, 25-27 August 2009, 657-659.

[15] Araar, A. and Khali, H. (2012) Investigating RFID Tags Fusion in a Clustered WSN Applied to Vehicle Identification and Tracking. International Journal of Computing and Information Technology, 1, 17-24.

[16] Lehpamer, H. (2008) RFID Design Principles. Artech House Microwave Library Inc., Boston, London.

[17] Kaur, M., Sandhu, M., Mohan, N. and Sandhu, P. (2011) RFID Technology Principles: Advantages, Limitations \& Its Applications. International Journal of Computer and Electrical Engineering, 3, 1793-1816. 